\title{
Moon Phases and Rates of Return of WIG Index on the Warsaw Stock Exchange
}

\author{
Krzysztof Borowski ${ }^{1}$ \\ ${ }^{1}$ Warsaw School of Economics, Warsaw, Poland \\ Correspondence: Krzysztof Borowski, Warsaw School of Economics, al. Niepodleglosci 162, 02-519 Warsaw, \\ Poland. Tel: 485-1027-5217. E-mail: krzysztof.borowski@sgh.waw.pl
}

Received: June 1, 2015

Accepted: July 2, 2015

Online Published: July 25, 2015

doi:10.5539/ijef.v7n8p256

URL: http://dx.doi.org/10.5539/ijef.v7n8p256

\begin{abstract}
The influence of the moon on human behavior have been featured in many, not only scientific publications. This paper tests the hypothesis that the one-session rates of return of index WIG (Warsaw Stock Exchange) in the period of 16.04.1991-31.03.2015, calculated for each of the following phases: full moon, new moon, first and third quarter, are statistically different form zero (at the significance level of 95\%). Calculations presented in this paper indicate that the one-session average rates of return for the sessions when the moon was in new phase, are statistically different from zero. In turn, the one-session average rates of return computed for each day of the week, when the moon was in one of analyzed phases (full, new, first and third quarter) did not differentiate from zero. However calculations of one-session average rates of return, regarding moon phases falling in a specific month displayed that they are statistically different from zero regarding: full moon sessions in February and June, the first quarter sessions in February and November, as well as the third quarter sessions in October.
\end{abstract}

Keywords: market efficiency, calendar effects, market anomalies

\section{Introduction}

\subsection{Introduction to the Problem of the Moon Influence on Investors Decisions}

In the scientific literature, there have been widespread conviction that moon cycles affect human behavior (Dichev \& Janes, 2003). Huston and Passerello (1971) proved that human beings exhibit more depressive behavior during the full moon. According to Wilkinson (1997) moon phases influences human anxiety and depression. In line with this academic research, moon phases affect also economic behavior of people (Lo \& Repin, 2001; Loewenstein, 2000) and investors' financial decisions (Dichev \& Janes, 2003). According to contemporary surveys "...a large part of the population, about $50 \%$, believes that strange behavior peaks around the full moon" (Kelly et al., 1996) and one may use "...stock prices as a powerful aggregators of regular and recurring human behavior" (Dichev \& Janes, 2001). The daily stock index data analyzed over decades and in many countries "..permits researchers to examine lunar cycle hypothesis on countless decisions of hundreds of millions of individuals" (Dichev \& Janes, 2001). In the scientific literature a statement can be found that the behavioral biases can impact investors decisions, thereby may influence stock and indices rates of return (Hirshleifer, 2001; Kahneman \& Riepe, 1998).

Relation between mood and stock returns was examined by Sauders (1993) and also by Hirshleifer and Shumway (2003), who proved that sunny weather was associated with an upbeat mood of investors and found the strong correlation between stock rates of return and sunshine. The Authors found that stock returns tended to be higher on sunny days. Taking into consideration seasonal time-variation of risk premia in stock returns, Kamstra et al. (2001), referring to yearly daylight fluctuations, introduced the Seasonal Affective Disorder (SAD) and found statistical significance relationship between stock returns and SAD. According to the Authors, the lack of sunlight induced investors depression, what increased their risk aversion and affected stock valuation.

The main purpose of this paper is to verify the null hypothesis that the one-session average rate of return calculated for the session, which falls during particular phase of the moon (full moon, new moon, first and third quarter), is statistically different from zero. The second aim of this paper is to verify the null hypothesis that the difference of one-session average rate of return calculated for the session, which falls during particular phase of the moon (full moon, new moon, first and third quarter), and the one-session average rate of return, calculated 
for all sessions, which not fall during particular phase of the moon, is equal zero. This is the first research regarding moon influence on rates of return on the polish equity market.

\subsection{Literature Review}

Crack (1999) proved that near new moon and full moon, stock markets volatility was higher and stock markets return were lower than during other periods. The same conclusion was offered by Gao (2009), analyzing rates of returns for two major stock markets of China during the period of 16 years. Dichev and Janes (2003) proved that returns during 15 days round new moon dates are about to double the returns in the 15 days round full moon dates for nearly all major stock indices of 24 analyzed, in the period of 30 years. In turn, Yuan et al. (2006) calculated relationship between lunar phases and stock market returns of 48 countries and found that rates of return were lower during the full moon than in the days around a new moon. The return difference was around 3\% to 5\% between new moon and full moon. Brahman et al. (2011), based on empirical study on seven stock markets in the period 1999-2009, confirmed previous research of Yuan et al. (2006). According to Sivakumar and Sathyyanarayanan (2009) the impact of lunar cycles on returns of the Bombay Stock Exchange index over the period of 17 years, was quite limited. Rotton and Kelly (1985) cite a working paper of Rotton and Rosenberg (1984), who investigated relation between lunar phases and closing prices of Dow Jones Industrial Average, and found no relation after correcting Dow Jones Industrial Average prices for first autocorrelations (Yuan et al., 2001).

Liu (2009) examined average daily returns, the correlation between consecutive daily returns, and the GARCH (Generalized Auto-Regressive Conditional Heteroskedasticity) volatility for 12 stock exchanges, including G-7 markets and 5 emerging markets in Asia, indicated the existence of the lunar impact on daily stock returns although different schemes were presented on each of the analyzed markets. Lempori (2009) investigating influence of eclipses on the rates or return on the US and Asian stock markets, in the period of 1928-2008, proved existence of below-average stock returns and trading volume declining during these events.

According to research conducted by Herbst (2007) the relationship between moon phases and market returns were vary and not consistent-moon cycles were not reliable in the process of predicting stock price returns and price volatility. Analyzing two periods of panic on the New York Stock Exchange in 1929 and 1987, and extending its study on all the panic examples from 1857 through 1987 on different markers, Carolan (1992) introduced spiral calendar, measuring distance between two important price extremes, not in hours or days but in Lunar Month Units.

The existence of a lunar cycle on precious metal returns was measured by Lucey (2008). According to the findings, the influence appeared to be the strongest in the silver than gold market, with very little evidence for a platinum market.

\section{Method}

The research is divided into six parts. In the first part, the following null hypothesis will be tested: the one-session average rate of return for the session, which falls during particular phase of the moon, is statistically different from zero. Appropriate statistical tests will be conducted for a confidence level of $95 \%$. In case of rejection of the null hypothesis, alternative hypothesis will be adopted, which was formulated in the following way: one-session average rate of return for the session, which falls during particular phase of the moon, is statistically different from zero. The hypothesis will be tested for the following moon phases: first quarter, full moon, third quarter and new moon. If a particular phase of the moon falls on Saturday or Sunday, then the one-day rate of return will be calculated for Friday and Monday sessions, respectively. On the other hand, when the analyzed phases of the moon falls on a holiday, the one-session rate of return will be calculated for the last session preceding the holiday. Close prices of the WIG index for two consecutive sessions will be used to compute one-session interest rates of return in the period of 16.04.1991-31.03.2015.

In the second part of the article the null hypothesis will be tested that the average rate of return of the WIG index between two consecutive new moons (full moons) is zero, and that the average rate of return of the WIG index between every second new moon (full moon) is statistically different from zero at the confidence level of $95 \%$. In the case of the portfolio replicating strategy, based on the every second new moon, registered rates of return were divided into two different groups: odd and even full moon phases from the first observed phase in 1991. A similar procedure was adopted in the case of the new moon phase sessions.

In the third part of this paper, the test for equality of two one-session average rates of return will be applied in the case of hypothesis testing. According to the adopted methodology, the survey covers two populations of returns, characterized by normal distributions. On the basis of two independent populations of rate of returns, 
which sizes are equal $n_{1}$ and $n_{2}$ respectively, the hypotheses $\mathrm{H}_{0}$ and $\mathrm{H}_{1}$ should be tested with the use of statistics $z$ (Osinska, 2006, pp. 43-44):

$$
\mathrm{z}=\frac{\overline{\mathrm{r}_{1}}-\overline{\mathrm{r}_{2}}}{\sqrt{\left(\frac{\mathrm{s}_{1}^{2}}{\mathrm{n}_{1}}+\frac{\mathrm{s}_{2}^{2}}{\mathrm{n}_{2}}\right)}}
$$

where:

$\overline{r_{1}}$-average rate of return in the first population,

$\overline{r_{2}}$-average rate of return in the second population,

$n_{1}$ - number of rates of return in the first population,

$n_{2}$ - number of rates of return in the second population,

$S_{1}^{2}$ - variance of rates of returns in the first population,

$S_{2}^{2}$ - variance of rates of returns in the second population.

The null hypothesis $H_{0}$ and alternative hypothesis $H_{l}$ can be formulated as follows:

$$
\begin{aligned}
H_{0}: E\left(r_{1}\right) & =E\left(r_{2}\right) \\
H_{1}: E\left(r_{1}\right) & \neq E\left(r_{2}\right)
\end{aligned}
$$

In particular: for the analysis of the one-session rates of return during the full moon, if $\overline{r_{1}}$ is the one-session average rate of return calculated for the sessions when full moon was observed, then $\overline{r_{2}}$ is the average rate of return for all sessions when full moon was not registered. In a similar way the calculation for the remaining three phases of the moon was performed.

In the fourth part of this paper the test for equality of two one-session average rates of return, calculated in a specific moon phase (full, new, first and third quarter), falling on a specific day of the week, will be applied in the case of hypothesis testing. And so, if the first population is composed of the rates of return calculated during the session, when the full moon coincided on Monday, then the second population determines the one-session rates of return for all remaining sessions during the week, e.g. on Tuesday, Wednesday, Thursday and Friday session. Similar calculations will be carried out taking into account the returns of the session, when the full moon falls on: Tuesdays, Wednesdays, Thursdays and Fridays, and then for remaining three moon phases.

In the fifth part of the paper the test for equality of two one-session average rates of return, calculated in a specific moon phase (full, new, 1 quarter, 3 quarter), falling on a specific month, will be exploited in the process of hypothesis testing. For example, if the first population are the rates of return calculated during the session, when the full moon was observed in January, then the second population determines the rates of return registered for all remaining sessions. Similar calculations will be carried out for all other months of the year, and then for the other three phases of the moon.

In the process of testing statistical hypothesis in the third, fourth and the fifth part of the paper, the formula F1 will be used as well as the p-value will be calculated. If the p-value is less than or equal to 0,05 ; then the hypothesis $H_{0}$ is rejected in favor of the hypothesis $H_{l}$. Otherwise, there is no reason to reject hypothesis $H_{0}$.

In the last part of this article statistics of the frequency of positive and negative returns will be presented, depending on whether a certain phase of the moon took place on a particular day of the week or in a particular month.

\section{Results}

\subsection{Analysis of the Average Rates of Return during a Specific Moon Phase}

The results of the analysis concerning moon phase are summarized in Table 1. For each of the moon phases the number of observations was equal 296, therefore in the process of verification statistical hypothesis, normal distribution test was used. The following principle was adopted in the row "Null hypothesis verification" in the Table 1. If there was no reason to reject the null hypothesis, then the word "TRUE" was placed in the cell, but when the null hypothesis was rejected in favor of the alternative hypothesis-the word "FALSE" was used.

Only in the case of the new moon, obtained one-session average rate of return, was higher than the confidence level, therefore the null hypothesis was rejected for the alternative hypothesis, which is formulated as follows: one-session average rate of return for the sessions, falling during new moon phase is statistically different from zero. The one-session average rate of return was lower than zero during the full moon sessions as well as for the 
third quarter session and equal: $-0,03014 \%$ and $-0,08407 \%$, respectively. One-session average rates of return, calculated for the new moon and first quarter session were higher than zero and mounted to: $0,33265 \%$ and $0,013031 \%$, respectively.

Table 1. Basic statistical data obtained for each of the moon phases (in the period of 16.04.1991-31.03.2015)

\begin{tabular}{lcccc}
\hline & Full moon & New moon & 1 quarter & 3 quarter \\
\cline { 2 - 5 } Average daily rate of return & $-0,0003$ & 0,0033 & 0,0013 & $-0,0008$ \\
Confidence level $(95,0 \%)$ & 0,0024 & 0,0024 & 0,0026 & 0,0023 \\
Null hypothesis verification & TRUE & FALSE & TRUE & TRUE \\
\hline
\end{tabular}

Note. The null hypothesis verification: "TRUE" - there is no reason to reject the null hypothesis, "FALSE" - the null hypothesis should be rejected in favor of the alternative hypothesis.

Source: own calculations

\subsection{Analysis of the Average Rates of Return between Two Consecutives New Moons (Full Moons) and between Every Second New Moon (Full Moon)}

According to the data in Table 2, average rate of return was statistically different form zero in all 6 analyzed strategies:

1. opening index replicating portfolio at close prices during the full (new) moon session and closing it at the close price during second successive full (new) moon-in total: 4 series of observations.

2. opening index replicating portfolio at close price during the full (new) moon and closing it at the close price at the end of the following full (new) moon session-in total: 2 series of observations.

Table 2. Basic statistical data obtained for the strategy of investing in index replicating portfolio between every second full moons and every second new moons, as well as between each full and new moons (in the period of 16.04.1991-31.03.2015)

\begin{tabular}{|c|c|c|c|c|c|c|}
\hline & \multicolumn{2}{|c|}{ Every second new moon } & \multicolumn{2}{|c|}{ Every second full moon } & \multirow[b]{2}{*}{$\begin{array}{l}\text { New moon - } \\
\text { new moon }\end{array}$} & \multirow[b]{2}{*}{$\begin{array}{l}\text { Full moon } \\
\text { full moon }\end{array}$} \\
\hline & $\begin{array}{c}\text { I series of } \\
\text { observations }\end{array}$ & $\begin{array}{c}\text { II series of } \\
\text { observations }\end{array}$ & $\begin{array}{c}\text { I series of } \\
\text { observations }\end{array}$ & $\begin{array}{c}\text { II series of } \\
\text { observations }\end{array}$ & & \\
\hline Average rate of return & $0,0418^{1}$ & $0,0402^{2}$ & $0,04156^{3}$ & $0,0421^{4}$ & 0,0189 & 0,0197 \\
\hline $\begin{array}{l}\text { Average rate of return between two } \\
\text { full or two new moon }\end{array}$ & 0,0209 & 0,0201 & 0,02079 & 0,0210 & 0,0189 & 0,0197 \\
\hline Confidence level $(95,0 \%)$ & 0,0307 & 0,0282 & 0,0323 & 0,0299 & 0,0120 & 0,0131 \\
\hline Null hypothesis verification & FALSE & FALSE & FALSE & FALSE & FALSE & FALSE \\
\hline
\end{tabular}

Note. ${ }^{1}$ In the period: new moon-second new moon after the first.

${ }^{2}$ In the period: new moon-second new moon after the first.

${ }^{3}$ In the period: full moon-second full moon after the first.

${ }^{4}$ In the period: full moon-second full moon after the first.

The null hypothesis verification: "TRUE" - there is no reason to reject the null hypothesis, "FALSE" - the null hypothesis should be rejected in favor of the alternative hypothesis.

Source: own calculations.

The average rate of return, calculated for the investment portfolio opened at the close prices in the full (new) moon session and closed at the close price during the following full (new) moon session, was equal to 1,886636\% (new moon-new moon strategy) and $1,96970 \%$ (full moon-full moon strategy). In turn, for all analyzed investment strategies, based on opening a portfolio during every second full or new moon phase, the average rate of return was higher than $4 \%$, e.g. two times more than in the case of the strategy based on opening and closing the investment during two consecutive moon phases (full moon-full moon or new moon-new moon).

\subsection{Test for Equality of Two One-Session Average Rates of Return}

The results of testing zero hypothesis with the use of average rates of returns for two different populations, are presented in the Table 3. 
Table 3. Basic statistical data obtained for the test of equality of two average rates of return (in the period of 16.04.1991-31.03.2015)

\begin{tabular}{lcccc}
\hline & Full moon & New moon & 1 quarter & 3 quarter \\
\cline { 2 - 5 } Average rate of return for analyzed group & $-0,0003$ & 0,0033 & 0,0013 & 0,0008 \\
Average rates of return for the other observations & 0,0009 & 0,0008 & 0,0009 & 0,0010 \\
p-value & 0,3416 & 0,0408 & 0,7466 & 0,1353 \\
p-value test & TRUE & FALSE & TRUE & TRUE \\
\hline
\end{tabular}

Note. The null hypothesis verification: "TRUE"-there is no reason to reject the null hypothesis, "FALSE"-the null hypothesis should be rejected in favor of the alternative hypothesis.

Source: own calculations.

Only in the case of one-session average rate of return, calculated during the session, when the new moon was observed, the p-value was less than 0,05 . This fact permits to reject the null hypothesis in favor of the alternative hypothesis. In the case of the remaining one-session rates of return calculated for sessions, when the moon was in one of the following phases: full moon, first or third quarter, there was no reason to reject null hypothesis.

The results obtained in this section are coherent with the calculations performed in the section 3.1

\subsection{Test for Equality of Two One-Session Average Rates of Return, When the Analyzed Moon Phase Falls on the} Specific Day of The Week

The results of testing zero hypothesis with the use of one-session average rates of returns for two different populations, divided due to the presence of specific phases of the moon on a given day of the week, are presented in the Table 4 and Table 5.

Table 4. Basic statistical data obtained for the test of equality of two average rates of return when the particular moon phase (full moon or new moon) falls on the specific day of the week (in the period of 16.04.1991-31.03.2015)

\begin{tabular}{|c|c|c|c|c|c|c|c|c|c|c|}
\hline & \multicolumn{5}{|c|}{ Full Moon } & \multicolumn{5}{|c|}{ New moon } \\
\hline & Monday & Tuesday & Wednesday & Thursday & Friday & Monday & Tuesday & Wednesday & Thursday & Friday \\
\hline $\begin{array}{l}\text { Average rate of return for } \\
\text { analyzed group }\end{array}$ & $-0,0009$ & 0,0007 & $-0,0032$ & 0,0015 & 0,0004 & 0,0031 & 0,0042 & 0,0044 & 0,0015 & 0,0034 \\
\hline $\begin{array}{l}\text { Average rates of return for } \\
\text { the other observations }\end{array}$ & $-0,0001$ & $-0,0005$ & 0,0002 & $-0,0006$ & $-0,0006$ & 0,0034 & 0,0032 & 0,0031 & 0,0036 & 0,0033 \\
\hline p-value & 0,7597 & 0,6549 & 0,4213 & 0,5953 & 0,7000 & 0,8967 & 0,7791 & 0,6794 & 0,5820 & 0,9417 \\
\hline p-value test & TRUE & TRUE & TRUE & TRUE & TRUE & TRUE & TRUE & TRUE & TRUE & TRUE \\
\hline
\end{tabular}

Note. The null hypothesis verification: "TRUE" - there is no reason to reject the null hypothesis, "FALSE" - the null hypothesis should be rejected in favor of the alternative hypothesis.

Source: own calculations.

Table 5. Basic statistical data obtained for the test of equality of two average rates of return when the particular moon phase $\left(1^{\text {st }}\right.$ or $3^{\text {rd }}$ quarter) falls on the specific day of the week (in the period of 16.04.1991-31.03.2015).

\begin{tabular}{ccccccccccccc}
\hline & \multicolumn{9}{c}{1 quarter } & \multicolumn{5}{c}{3 quarter } \\
\cline { 2 - 11 } & Monday & Tuesday & Wednesday & Thursday & Friday & Monday & Tuesday & Wednesday & Thursday & Friday \\
\cline { 2 - 11 } $\begin{array}{c}\text { Average rate of return for } \\
\text { analyzed group }\end{array}$ & 0,0003 & 0,0047 & $-0,0022$ & $-0,0002$ & 0,0030 & $-0,0015$ & 0,0012 & 0,0014 & $-0,0016$ & $-0,0020$ \\
$\begin{array}{c}\text { Average rates of return for } \\
\text { the other observations } \\
\text { p-value }\end{array}$ & 0,0017 & 0,0007 & 0,0019 & 0,0016 & 0,0007 & $-0,0005$ & $-0,0012$ & $-0,0012$ & $-0,0007$ & $-0,0004$ \\
p-value test & 0,6229 & 0,4279 & 0,3148 & 0,5862 & 0,3860 & 0,7307 & 0,4722 & 0,4510 & 0,7785 & 0,4844 \\
& TRUE & TRUE & TRUE & TRUE & TRUE & TRUE & TRUE & TRUE & TRUE & TRUE \\
\hline
\end{tabular}

Note. The null hypothesis verification: "TRUE" - there is no reason to reject the null hypothesis, "FALSE" - the null hypothesis should be rejected in favor of the alternative hypothesis.

Source: own calculations. 
In all of the analyzed cases, the p-value was higher than 0,05 ; and therefore there was no reason to reject the null hypothesis. Thus, one-session average rate of return, calculated for each day of the week, when the specific moon phase falls on, was equal to the average one-session rate of return obtained for all other cases (for the confidence level of $95 \%)$.

\subsection{Test for Equality of Two Average Rates of Return, When the Analyzed Moon Phase Falls during the Specific} Month of Year

Because the number of observation in this case was lower than 30, then Student's t-statistics was applied in the process of hypothesis testing. The results of testing zero hypothesis are presented in Table 1A (Apendix).

The null hypothesis was rejected in favor of the alternative hypothesis in the following cases (in parentheses, p-values are given):

1. the one-session average rate of return calculated for full moon falling in February $(0,0210)$ and in June $(0,0112)$,

2. the one-session average return calculated for the first quarter falling in February $(0,0447)$ and in November $(0,0196)$,

3. the one-session average return calculated for the third quarter falling in October $(0,0380)$.

In all other cases, there was no reason to reject the null hypothesis.

\subsection{The Percentage of Negative and Positive One-Session Rates of Return in View of Moon Phase}

The percentage of positive and negative one-session returns for WIG index for each phase of the moon, is presented in Table 6. The highest percentage of positive one-session rates of return $(55,07 \%)$ was observed during the session coinciding with new moon, and the lowest was registered for the third quarter moon session $(47,64 \%)$.

Table 6. The number and percentage of positive and negative one-session rates of return concerning WIG index broken due to the moon phases (in the period of 16.04.1991-31.03.2015)

\begin{tabular}{lccccc} 
& & Full moon & New moon & 1 quarter & 3 quarter \\
\cline { 2 - 5 } & Percentage of positive rates of return & $52,03 \%$ & $55,07 \%$ & $51,01 \%$ & $47,64 \%$ \\
Percentage of negative rates of return & $47,97 \%$ & $44,93 \%$ & $48,99 \%$ & $52,36 \%$ \\
\hline
\end{tabular}

Source: own calculations.

The number and percentage of positive and negative one-session returns for WIG index for each moon phase falling on specific day of the week, is presented in Table 7.

In the case, when the full moon was observed during Friday session, the percentage of positive one-session rates of return was the highest and equal 54,32\%, while during Thursday session was the lowest and equal 47,73\%. The highest percentage of positive one-session rates of return for new moon session, as well as for the first quarter session was observed on Mondays and equal 63,22\% and 57,14\%, respectively. For the session, when the moon was in the third phase, the percentage of positive one-session rates of returns was the highest on Mondays and Thursdays, when mounted to $50 \%$ in both cases.

When the moon was in the full phase, the positive rate of return was the most frequently observed in February $(69,57 \%)$ and the least in June (25\%)-see table A2 in Apendix. For the new moon session, the greatest percentage of positive rates of return was registered in November $(69,57 \%)$, and the lowest in September $(41,67 \%)$. When the session occurred during the first quarter of moon, the highest percentage of positive rates of return took place in February $(82,61 \%)$, and the lowest in April $(25,00 \%)$. For the third quarter, the highest percentage of positive rates of return appeared in October $(65,38 \%)$, and the lowest in December $(33,33 \%)$. 
Table 7. The number and percentage of positive and negative one-session rates of return for WIG index broken due to the moon phases falling on a specific day of the week (in the period of 16.04.1991-31.03.2015)

\begin{tabular}{lllllll}
\hline Moon phase & & Monday & Tuesday & Wednesday & Thursday & Friday \\
\hline \multirow{2}{*}{ Full moon } & Percentage of positive rates of return & $51,14 \%$ & $53,85 \%$ & $52,27 \%$ & $47,73 \%$ & $54,32 \%$ \\
& Percentage of negative rates of return & $48,86 \%$ & $46,15 \%$ & $47,73 \%$ & $52,27 \%$ & $45,68 \%$ \\
\multirow{2}{*}{ New moon } & Percentage of positive rates of return & $63,22 \%$ & $53,66 \%$ & $52,38 \%$ & $48,78 \%$ & $51,19 \%$ \\
& Percentage of negative rates of return & $36,78 \%$ & $46,34 \%$ & $47,62 \%$ & $51,22 \%$ & $48,81 \%$ \\
\multirow{2}{*}{$1^{\text {st }}$ quarter } & Percentage of positive rates of return & $57,14 \%$ & $45,45 \%$ & $48,78 \%$ & $41,86 \%$ & $54,22 \%$ \\
& Percentage of negative rates of return & $42,86 \%$ & $54,55 \%$ & $51,22 \%$ & $58,14 \%$ & $45,78 \%$ \\
\multirow{2}{*}{$3^{\text {rd }}$ quarter } & Percentage of positive rates of return & $50,00 \%$ & $48,78 \%$ & $47,83 \%$ & $50,00 \%$ & $44,05 \%$ \\
& Percentage of negative rates of return & $50,00 \%$ & $51,22 \%$ & $52,17 \%$ & $50,00 \%$ & $55,95 \%$ \\
\hline
\end{tabular}

Source: own calculations.

\section{Discussion}

The relationship between the moon phases and rates of return on sizeable group of world stock exchanges have already been raised in scientific papers. The author of this article focused mostly on the relationship between rates of return during sessions close to the four moon phases (new, 1st quarter, full and 3rd quarter) while the other authors, in their research concentrated rather on the rates of return calculated during a couple of sessions around the full or new moon (Dichev \& Janes, 2001). Therefore the comparison of achieved outcome in this paper with the result obtained by other authors, is rather difficult.

This paper is one of the first dedicated to the study of the statistical significance of the rates of return on the Polish stock market calculated for different moon phases. Furthermore, these relationships are not only considering the new and full moon phases, but also take into account the session when the moon was in the first or third quarter.

As it was proved in the paper, a different from zero and statistically significant one-session average rate of return of the WIG index, was calculated for the sessions coincided with the new moon. The outcome may be regarded as a part of the ongoing discussions on the hypothesis of financial markets efficiency, which was introduced by Fama (1970).

\section{References}

Brahman, R., Hooy, C., \& Ahmad, Z. (2011). Moon effect on Pacific basin stock market. Indonesian Market Review, 3, 117-126.

Carolan, C. (1992). Spiral calendar. New York: New Classic Library.

Crack, T. (1999). A classic case of "data snooping” for classroom discussion. Journal of Financial Education, 25, 92-97.

Dichev, I., \& Janes, T. (2003). Lunar cycle effects in stock returns. Journal of Private Equity, 6, 8-29.

Fama, E. (1970). Efficient capital markets: A review of theory and empirical work. Journal of Finance, 25, 383-417. http://dx.doi.org/10.2307/2325486

Gao, Q. (2009). Lunar phases effect in Chines stock returns. International Conference on Business Intelligence and Financial Engineering. Beijing, China.

Herbst A. (2007). Lunacy in the stock markets-what is the evidence? Journal of Biomechanics, 9, 1-18. http://dx.doi.org/10.1007/s10818-007-9016-3

Hirshleifer, D. (2001). Investor psychology and asset pricing. Journal of Finance, 56, 1533-1597. http://dx.doi.org/10.1111/0022-1082.00379

Hirshleifer, D., \& Shumway, T. (2003). Good day sunshine: Stock markets returns and the weather. Journal of Finance, 58, 1009-1032. http://dx.doi.org/10.1111/1540-6261.00556

Huston, R., \& Pasarello, C. (1971). On the dynamics of a human body model. Journal of Biomechanics, 9, 369-378. http://dx.doi.org/10.1016/0021-9290(71)90057-1

Kahneman, D., \& Riepe, M. (1998). Aspects of investor psychology: Beliefs, preferences and biases investments advisors should know about. Journal of Portfolio Management, 24. 
http://dx.doi.org/10.3905/jpm.1998.409643

Kamstra, M., Kramer, L., \& Levi, M. (2001). Winter blues: Seasonal Affective Disorder (SAD) and stock market returns. Working paper, University of British Columbia.

Kelly, I., Rotton, J., \& Culver, R. (1996). The moon was full and nothing happened: A review of studies on the moon and human behavior and human belief. In J. Nickel, B. Karr, \& T. Genoni (Eds.), The outer edge. Committee for the Scientific Investigation of Claims of the Paranormal (CSICOP), Amherst, NY.

Lempori, G. (2009). Dark omens in the sky: Do superstitious beliefs affect investment decisions? Working Paper, Copenhagen Business School.

Liu, S. (2009). A Bayesian analysis of lunar effects on stock returns. Working Paper, Shih Hsin University, Department of Finance. http://dx.doi.org/10.2139/ssrn.1366663

Lo, A., \& Repin, D. (2001). The psychophysiology of real time financial risk procession. Sloan Working Paper 4223.01, MIT Sloan School of Management.

Loewenstein, G. (2000). Emotion in economic theory and economic behavior. American Economic Reviews, 90, 426-432. http://dx.doi.org/10.1257/aer.90.2.426

Lucey, B. (2010). Lunar seasonality in precious metal returns. Applied Economics Letters, 18, 835-838, http://dx.doi.org/10.1080/17446540802516188

Osinska, M. (2006). Ekonometria finansowa. Warszawa: PWE.

Rotton, J., \& Kelly, I. (1985). Much ado about the full moon: A meta-analysis of lunar-lunacy research. Psychological Bulletin, 97, 296-306. http://dx.doi.org/10.1037/0033-2909.97.2.286

Rotton, J., \& Rosenberg, M. (1984). Lunar cycles and the stock market: Time-series analysis for environmental psychologists. Unpublished Manuscript, Florida International University.

Saunders, E. (1993). Stock prices and Wall Street weather. American Economic Review, 83, 1337-1345.

Sivakumar, N., \& Sathyyanarayanan, S. (2009). Do Krishna Paksha (new moon phase) and Shukla Paksha (Full moon phase) affect the Indian stock market? A study of lunar cycles in the Bombay Stock Exchange. International Journal of Indian Culture \& Business Management, 3, 281-294. http://dx.doi.org/10.1504/IJICBM.2009.023549

Wilkinson, G. (1997). Lunar cycle and consultation for anxiety and depression in general practice. International Journal of Social Psychiatry, 43, 29-34. http://dx.doi.org/10.1177/002076409704300103

Yuan, K., Zheng, L., \& Zhu, Q. (2006). Are investors moonstruck? Lunar phases and stock returns. Journal of Empirical Finance, 13, 1-23. http://dx.doi.org/10.1016/j.jempfin.2005.06.001

\section{Appendix A}

Table A1. Basic statistical data obtained for the test of equality of two average rates of return when the particular moon phase falls in the specific month of year (in the period of 16.04.1991-31.03.2015)

\begin{tabular}{|c|c|c|c|c|c|c|c|c|c|c|c|c|}
\hline & January & Tebruary & March & April & May & June & July & August & September & October & November & December \\
\hline p-value (full moon) & 0,8446 & 0,0210 & 0,7337 & 0,2477 & 0,5458 & 0,0112 & 0,3587 & 0,8470 & 0,6690 & 0,4667 & 0,3569 & 0,4357 \\
\hline p-value (new moon) & 0,6863 & 0,5177 & 0,3558 & 0,4297 & 0,6076 & 0,7763 & 0,4357 & 0,9448 & 0,1420 & 0,4951 & 0,1669 & 0,4776 \\
\hline $\mathrm{p}$-value ( $1^{\text {st }}$ quarter $)$ & 0,7547 & 0,0447 & 0,1774 & & 0,2193 & 0,8447 & 0,9619 & 0,7393 & 0,7811 & 0,6266 & 0,0196 & 0,4773 \\
\hline $\mathrm{p}$-value ( $3^{\text {st }}$ quarter $)$ & 0,7986 & 0,4467 & 0,3379 & 0,9122 & 0,1245 & 0,4048 & 0,4912 & 0,1665 & 0,7989 & 0,0380 & 0,4938 & 0,4171 \\
\hline
\end{tabular}

Note. The p-values higher than 0,05 (rejection of the null hypothesis) are written in italics.

Source: own calculations. 
Table A2. The number and percentage of positive and negative one-session rates of return for WIG index broken due to the moon phases falling in a specific month of year (in the period of 16.04.1991-31.03.2015)

\begin{tabular}{|c|c|c|c|c|c|c|c|c|c|c|c|c|c|}
\hline & & January & February & March & April & may & June & July & August & Septemb & October & November & December \\
\hline \multirow{2}{*}{$\begin{array}{l}\text { Full } \\
\text { moon }\end{array}$} & $\begin{array}{l}\text { Percentage of positive } \\
\text { rates of return }\end{array}$ & $54,17 \%$ & $69,57 \%$ & $61,54 \%$ & $66,67 \%$ & $48,00 \%$ & $25,00 \%$ & $53,85 \%$ & $40,00 \%$ & $52,00 \%$ & $50,00 \%$ & $48,00 \%$ & $56,00 \%$ \\
\hline & $\begin{array}{l}\text { Percentage of negative } \\
\text { rates of return }\end{array}$ & $45,83 \%$ & $30,43 \%$ & $38,46 \%$ & $33,33 \%$ & $52,00 \%$ & $75,00 \%$ & $46,15 \%$ & $60,00 \%$ & $48,00 \%$ & $50,00 \%$ & $52,00 \%$ & $44,00 \%$ \\
\hline \multirow{2}{*}{$\begin{array}{l}\text { New } \\
\text { moon }\end{array}$} & $\begin{array}{l}\text { Percentage of positive } \\
\text { rates of return }\end{array}$ & $59,26 \%$ & $63,64 \%$ & $45,83 \%$ & $52,17 \%$ & $48,00 \%$ & $53,85 \%$ & $56,00 \%$ & $64,00 \%$ & $41,67 \%$ & $48,00 \%$ & $69,57 \%$ & $57,69 \%$ \\
\hline & $\begin{array}{l}\text { Percentage of negative } \\
\text { rates of return }\end{array}$ & $40,74 \%$ & $36,36 \%$ & $54,17 \%$ & $47,83 \%$ & $52,00 \%$ & $46,15 \%$ & $44,00 \%$ & $36,00 \%$ & $58,33 \%$ & $52,00 \%$ & $30,43 \%$ & $42,31 \%$ \\
\hline \multirow{2}{*}{$\begin{array}{l}1^{\text {st }} \\
\text { quarter }\end{array}$} & $\begin{array}{l}\text { Percentage of positive } \\
\text { rates of return }\end{array}$ & $60,00 \%$ & $82,61 \%$ & $48,00 \%$ & $25,00 \%$ & $62,50 \%$ & $64,00 \%$ & $52,00 \%$ & $52,00 \%$ & $50,00 \%$ & $40,74 \%$ & $34,78 \%$ & $44,00 \%$ \\
\hline & $\begin{array}{l}\text { Percentage of negative } \\
\text { rates of return }\end{array}$ & $40,00 \%$ & $17,39 \%$ & $52,00 \%$ & $75,00 \%$ & $37,50 \%$ & $36,00 \%$ & $48,00 \%$ & $48,00 \%$ & $50,00 \%$ & $59,26 \%$ & $65,22 \%$ & $56,00 \%$ \\
\hline \multirow{2}{*}{$\begin{array}{l}3^{\text {rd }} \\
\text { quarter }\end{array}$} & $\begin{array}{l}\text { Percentage of positive } \\
\text { rates of return }\end{array}$ & $52,00 \%$ & $34,78 \%$ & $29,17 \%$ & $52,17 \%$ & $42,31 \%$ & $50,00 \%$ & $44,00 \%$ & $56,00 \%$ & $50,00 \%$ & $65,38 \%$ & $61,54 \%$ & $33,33 \%$ \\
\hline & $\begin{array}{l}\text { Percentage of negative } \\
\text { rates of return }\end{array}$ & $48,00 \%$ & $65,22 \%$ & $70,83 \%$ & $47,83 \%$ & $57,69 \%$ & $50,00 \%$ & $56,00 \%$ & $44,00 \%$ & $50,00 \%$ & $34,62 \%$ & $38,46 \%$ & $66,67 \%$ \\
\hline
\end{tabular}

Source: own calculations.

\section{Copyrights}

Copyright for this article is retained by the author(s), with first publication rights granted to the journal.

This is an open-access article distributed under the terms and conditions of the Creative Commons Attribution license (http://creativecommons.org/licenses/by/3.0/). 